\title{
Incorporating gender specific land-use decisions in agent-based land use models
}

\author{
G.B. Villamor ${ }^{\text {a }}$ and M. van Noordwijk ${ }^{\text {b }}$ \\ a Department of Ecology and Natural Resource Management, Center for Development Research (ZEF), \\ University of Bonn, Germany; \\ ${ }^{b}$ World Agroforestry Centre (ICRAF), SE Regional Office, Bogor, Indonesia \\ Email: gracev@uni-bonn.de
}

\begin{abstract}
Gender specificity in response to land-use options and agents offering new investment opportunities has received little attention to date. It may influence ecosystem services delivery especially to areas under conservation agreements (such as those targeting reduced emissions from deforestation and degradation). This study compares the land-use decisions of men and women, and assesses the implications of their decisions on provisioning of ecosystem services in the context of the Minangkabau ethnic group in central Sumatra, Indonesia. This is the largest matrilineal society in the world and men and women farmers have their own management decisions with regards to their land. In this paper, we explored how men and women differ in terms of land-use perspectives and ecosystem services' preferences and how these differences affect the land-use pattern and delivery ecosystem services. Due to its complexities, we combined sex-disaggregated surveys and role-playing games to parameterize the gender-specific agent decision making; and simulated the agent-based model (i.e., Land Use DynAmic Simulator or LUDAS) to explore the effect of the disparities between men and women in land-use decision making. In this paper, we present the key factors that make the two different based on the abovementioned methods. The simulations showed gender specific trends of land-use change; a majority of men preferred tree-based system (such as rubber agroforestry), whereas a majority of women preferred food and cash-based crops. Thus, women-dominated landscapes emitted more carbon than men-dominated landscapes. On the other hand, provision of ecosystem services is affected by gender specific roles, which often been misrepresented in many land-use change models.
\end{abstract}

Keywords: Decision making, ecosystem services, heterogeneity, land-use preference, matrilineal society 
Villamor and van Noordwijk., Incorporating gender specific land-use decisions in agent-based land use models

\section{INTRODUCTION}

Gender specificity in response to land-use options and agents offering new investment opportunities has received little attention to date (van Noordwijk et al., 2014; Villamor et al., 2014c). We explored the key research questions of how men and women differ in terms of land-use perspectives and ecosystem services preferences and how these differences affect the land-use pattern and delivery of ecosystem services. This question is to address the concept of heterogeneity in the social system that influences the dynamics of the ecological systems. Most of the agent-based models on understanding land-use dynamics treat household as a unit of analysis. However, these individuals within a household have diverse strategies, attributes and decision making. In this paper, we recognize that gender is among the many characteristics that make up households in terms of decision making. We explore effect of gender-specific land-use decisions in land-use change and associated effects on ecosystem services. One reason for this gap is because studies of the interactions between gender and environment are mostly treated in a static manner (Meinzen-Dick et al., 2014). This paper presents the empirical parameterization of agents' land-use decision-making in the context of the matrilineal society of the Minangkabau in central Sumatra and assesses the implications of their decisions on provisioning of ecosystem services.

\section{WHY GENDER?}

The Minangkabau in West Sumatra, Indonesia is the largest surviving matrilineal society in the world. In this society, marriage is matrilocal and women landholders dominate the landscape as effective heads of households, which are built around matrilineal ties and actively farm their own lands with the help of husbands (Blackwood, 2008). Both men and women have distinct land-use management. Men are involved in tree-based systems (e.g., rubber agroforest) and women are involved in (rain fed) rice production. However, the Sumatran landscape has experienced drastic economic and landscape transformations since 1990s, where most of the lowland areas (with lowland forests and agroforests) have been converted to oil palm and rubber plantations, as an economic engine of the region (van Noordwijk et al., 2012). In the study of land-use decisions using role-playing games (Villamor et al., 2014a), there is clear distinction between men and women's ways of approaching actors promoting conservation or conversion of the landscapes as well as their land-use preference. The questions of how do men and women differ in terms of their land-use perspectives and ecosystem services preferences and how these differences affect the land-use pattern and delivery of ecosystem services are pertinent in understanding the link between environmental sustainability and gender equality (van Noordwijk and Villamor, 2014).

\section{METHODOLOGY}

\subsection{Study area}

The study area is located in Bungo district, Jambi Province, central part of Sumatra, which involves three villages as part of Minangkabau culture (Figure 1). Its total area is about 15,000 ha. More than 30\% of the remaining forest and rubber agroforests have been converted to monoculture (Ekadinata and Vincent, 2011), whereas the rice fields along the main roads have been converted to oil palm (Villamor et al., 2015). Among the five major land use types in the study area are forest, rubber agroforest (hereafter as agroforest), rubber monoculture (hereafter as monoculture), rice field and oil palm.

\subsection{LB-LUDAS model}

The LB-LUDAS (Lubuk Beringin - Land Use DynAmic Simulator) ${ }^{1}$ model was used to simulate the genderspecific land-use decision making. It is an agent-based land use model. The model was implemented in the same study area in Indonesia with the main purpose of to explore the potential trade-offs and synergies of policy interventions on the goods and services over space and time, which focuses only on men-dominated landscapes (Villamor et al., 2014b). The full description using Overview, Design concept, and Details (ODD) protocol is presented in Villamor et al. (2014b). In this paper, the description of the decision-making is described using the extended ODD+ Decisions protocol developed by Müller et al. (2013) by focusing on the subsection of Individual Decision-Making (Table 1).

Ecosystem services are assessed based on the yields of rice (food), rubber agroforest (both for livelihood and agro-biodiversity indicators) and rubber monoculture (livelihood), and carbon sequestration potential resulting from the land-use change. Among the input data used is the 2005 land-use map as an initial map

\footnotetext{
${ }^{1}$ LUDAS is an agent-based modeling platform developed by Le et al. (2008).
} 
Villamor and van Noordwijk., Incorporating gender specific land-use decisions in agent-based land use models

Table 1. Decisions protocol description for LB-LUDAS

\begin{tabular}{|c|c|c|}
\hline Design concept & Guiding questions & LB-LUDAS model \\
\hline \multirow[t]{8}{*}{$\begin{array}{l}\text { Individual } \\
\text { decision making }\end{array}$} & $\begin{array}{l}\text { What are the subjects and objects of the decision- } \\
\text { making? On which level of aggregation is decision- } \\
\text { making modelled? Are multiple levels of decision } \\
\text { making included? }\end{array}$ & $\begin{array}{l}\text { Two types of subjects are (1) men, and (2) women, } \\
\text { which decide about the land use in their own farm plots. } \\
\text { Farm plots are the objects. Decisions made at higher } \\
\text { level (as a scenario) affect the decisions made at the } \\
\text { lower level. No multiple levels included. }\end{array}$ \\
\hline & $\begin{array}{l}\text { What is the basic rationality behind agent decision- } \\
\text { making in the model? Do agents pursue an explicit } \\
\text { objective or have other success criteria? }\end{array}$ & $\begin{array}{l}\text { This model follows the bounded rationality (or } \\
\text { condition-based) with limited information. There is no } \\
\text { explicit objective. }\end{array}$ \\
\hline & How do agents make their decisions? & $\begin{array}{l}\text { The agents make decisions whether to open/change } \\
\text { existing practices by calculating the probability (see } \\
\text { section 3.3). Preference coefficients were derived from } \\
\text { regression analysis and integrated in the } \\
\text { FarmlandChoice module (Le et al., 2008), where a } \\
\text { decision algorithm is included (Villamor et al., 2014b). }\end{array}$ \\
\hline & $\begin{array}{l}\text { Do the agents adapt their behavior to changing } \\
\text { endogenous and exogenous state variables? And if } \\
\text { yes, how? }\end{array}$ & Yes, Update-status sub-model (Le et al., 2008) \\
\hline & $\begin{array}{l}\text { Do social norms or cultural values play a role in the } \\
\text { decision-making process? }\end{array}$ & Yes. Social norms are so important (see section 3.4) \\
\hline & $\begin{array}{l}\text { Do spatial aspects play a role in the decision } \\
\text { process? }\end{array}$ & Yes \\
\hline & $\begin{array}{l}\text { Do temporal aspects play a role in the decision } \\
\text { process? }\end{array}$ & Yes \\
\hline & $\begin{array}{l}\text { To which extent and how is uncertainty included in } \\
\text { the agents' decision rules? }\end{array}$ & $\begin{array}{l}\text { Uncertainty is included in the calculation of the } \\
\text { probabilities to change land use in the form of standard } \\
\text { deviation. }\end{array}$ \\
\hline
\end{tabular}

simulated for a period of five years to conform to the time step used for the role-playing games (see section 3.4) whereas for carbon densities of each land use type, we used the data from Rahayu (2009). A total of five runs (i.e., simulations) were performed, and we considered the average of the key indicators. Two scenarios were simulated based on the decision making: (1) the business-as-usual (BAU) and (2) with payment for ecosystem services scheme (PES).

\subsection{Empirical parameterization of decision making}

Decision making of the agents in the study site was parameterized using sex-disaggregated surveys and roleplaying games (RPGs). A total of 184 household respondents were involved, of which $96(49 \%)$ were men and 98 (51\%) were women. The survey questionnaire explores whether they will change their current land-use practices and whether they would adopt PES to keep the existing rubber agroforests (dominant land use in the study area). To capture heterogeneity, household respondents by sex were categorized using principal component analysis and k-cluster analysis. There are two household types per gender, (1) relatively betteroff and (2) relatively poor households. In each household type, choice to change the current land use and willingness to adopt PES scheme were estimated using binary logistic regression whereas their land-use choices were estimated using multinomial logistic regression (Villamor, 2012). In Figure 1, factors

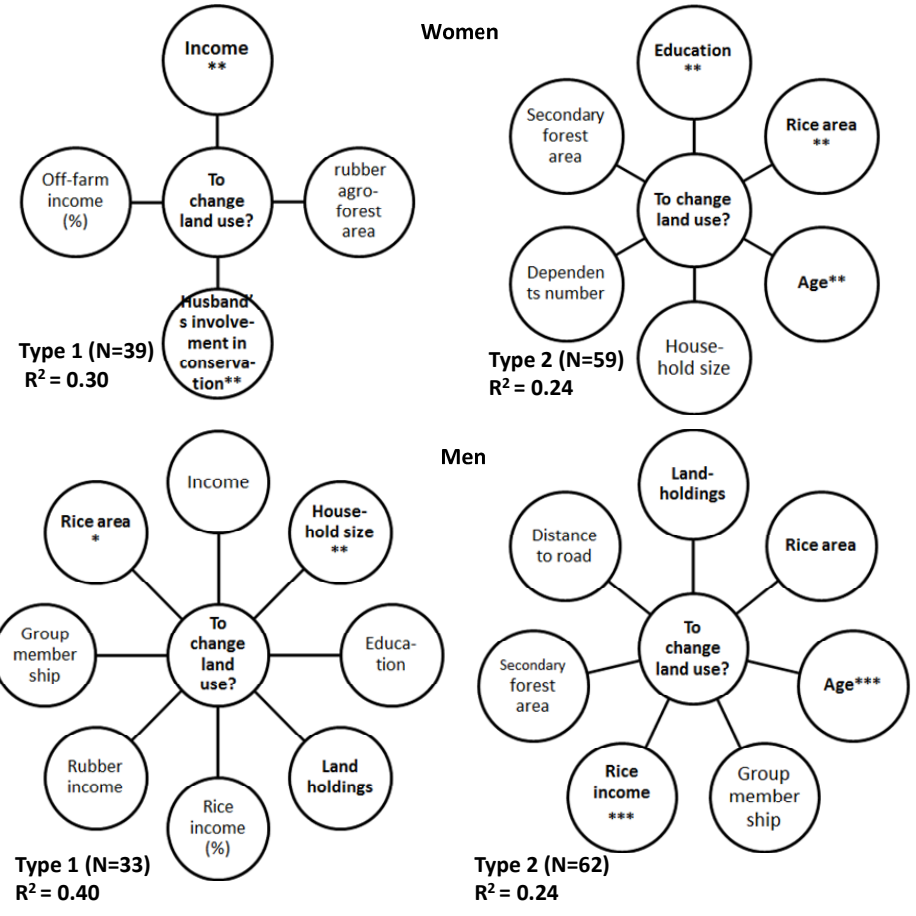

Figure 1. Variables associated with the decision to change land use according to typology and gender. 
Villamor and van Noordwijk., Incorporating gender specific land-use decisions in agent-based land use models

associated with the land-use change vary according to gender and household type. From the regression results, decision algorithm were developed (Villamor et al., 2014b) and incorporated in FarmlandChoice submodel of LUDAS. The survey also identified the key ecosystem services associated with specific land-use type of the respondents' choice as well as the level of importance.

The use of RPGs captures the external actors promoting conversion and conservation of existing land use. Men and women groups were disaggregated and subjected to these external actors to see if they would accept their offers to conserve or convert their existing land uses.

\subsection{Validation}

We validate the model outputs based on how they represent the real world behavior through construct validity (Parker et al., 2003; Villamor et al., 2013). We used RPGs both for parameterization of agents' behavior and as a form of social validation based on the outputs of the games (see Section 5). The players of the games were the same respondents of the survey and the outputs from the games were compared with the results of the simulation. However, the detailed results are not presented in this paper. For detail description and procedures of the game, see Villamor et al. (2014a).

\section{RESULTS}

\subsection{Land-use change}

The land-use trends simulated under the BAU and PES scenarios between men- and women dominated landscapes are presented in Figure 2. Under the BAU scenario, the average area of agroforest is higher in men than in women whereas the average area of monoculture rubber is higher in women than in men. Under the PES scenario, the average area of monoculture rubber is higher in women-dominated landscape than in men-dominated landscape whereas the average area of agroforest is higher in men-dominated landscape. In terms of rice area, the average area is higher in women-dominated landscape under the PES scenario, while the average rice area in men-dominated landscape is constant under both scenarios.

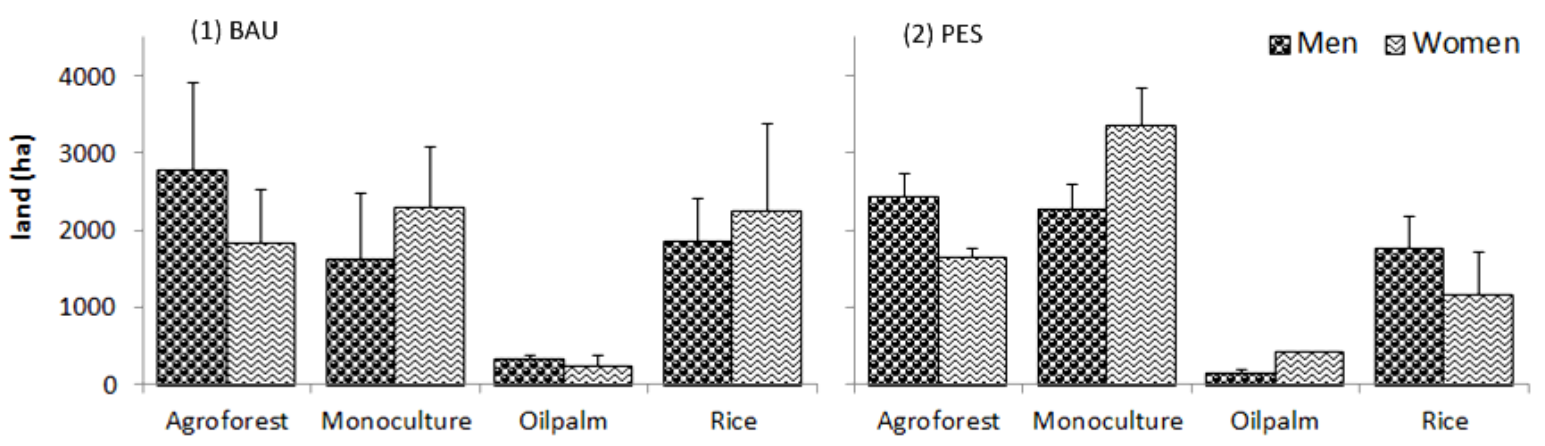

Figure 2. Land-use trends between men and women dominated landscapes.

The simulated land-use changes based on RPG between men and women groups are illustrated in Figure 3. Changes of land use were only observed in women groups, which they logged forests and then later converted to oil palm. All the men groups maintained their landscapes.

\subsection{Ecosystem services}

In terms of ecosystem services, simulated yields of three key indicators are depicted in Figure 4. Based on the (i.e., overlapping or non-overlapping) confidence intervals in Figure 4, there is no significant difference in agroforest yields between gender types in both scenarios. However, the agroforest

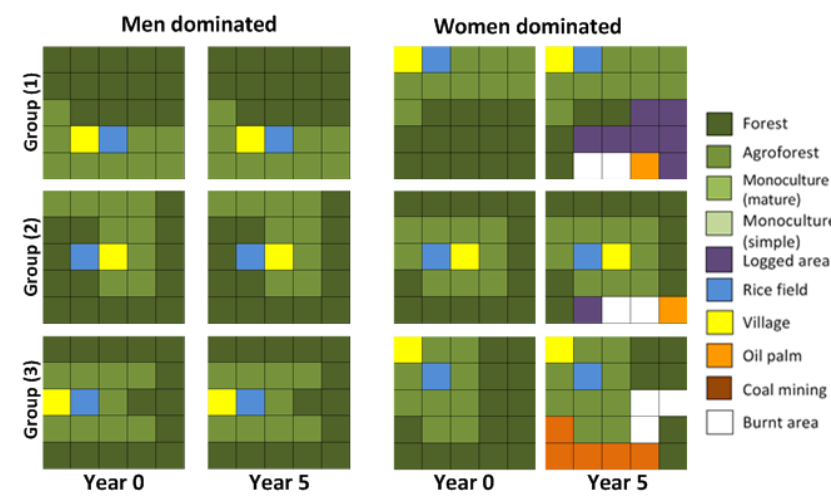

Figure 3. Simulated land-use changes from role-playing games between men and women. Note: Scenarios such as natural forest fire (i.e., burnt areas), increase in population, and other land uses (e.g., coal mining) were included. 
Villamor and van Noordwijk., Incorporating gender specific land-use decisions in agent-based land use models

yields are higher under PES scenario in both gender types. In terms of monoculture rubber, the significantly higher yield is produced by men under both scenarios.
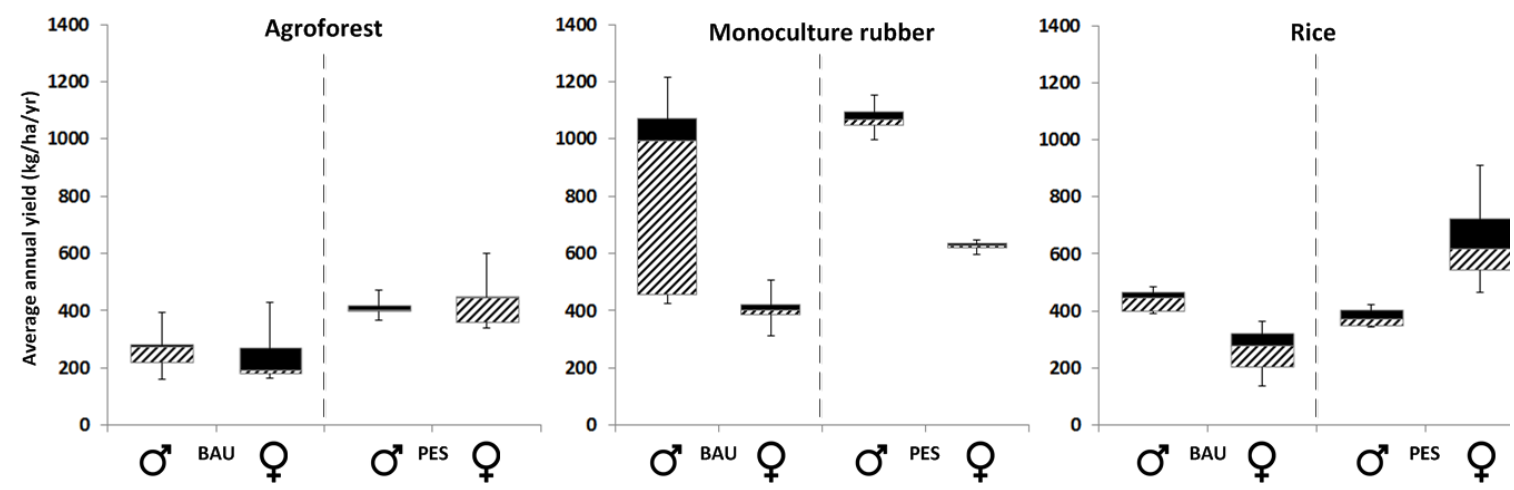

Figure 4. Differences in the average yields of agroforest, monoculture rubber and rice simulated under two scenarios (i.e., BAU and PES); vertical segments are the confidence interval (95\%) of the means.

Note: Confidence intervals are used to show the degree of overlap.

For rice production, the average yield is significantly higher in men-dominated landscape under the BAU scenario while the average yield is significantly higher in women-dominated landscape under the PES scenario.

With regards to potential carbon emissions resulting from land-use changes, the estimated emissions are shown in Figure 5. Result shows that men-dominated landscape emitted almost 50\% less carbon than women from land-use changes under both scenarios. PES schemes resulted in less carbon emission in contrast to the BAU scenario by both gender types.

\section{DISCUSSION AND CONCLUSIONS}

The findings from both LB-LUDAS and RPG simulations show that gender-specific land-use decision making affects landscape multi-functionality

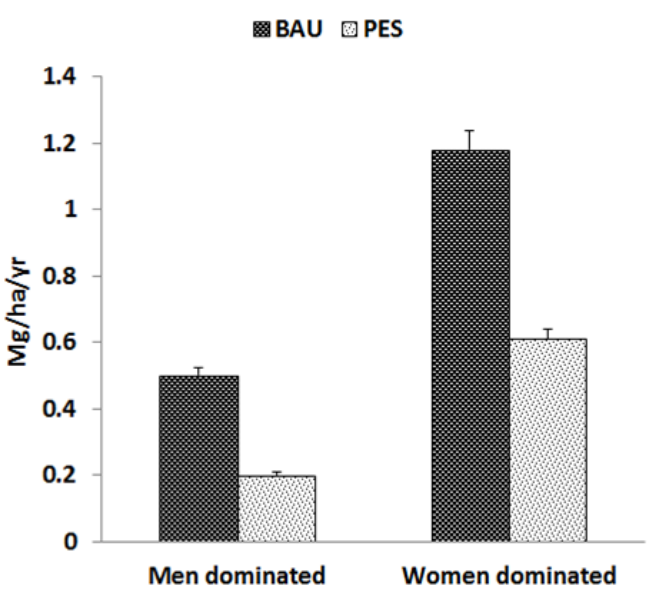

Figure 5. Estimated carbon emissions from simulated land-use changes under two scenarios. in terms of land-use trends and ecosystem services provision. Women's preferences are towards monoculture rubber (for livelihood purposes) and rice fields (for household consumption) while men's preferences are relatively unaffected by different scenarios (Figure 2). Under PES scheme, women would convert more land into monoculture rubber and oil palm probably because of higher income return as compared to agroforest even if subjected to PES scheme (Villamor et al., 2014b). This observation is supported by the result of RPG, in which all the women groups logged the forests and turned into oil palm (Figure 3). On the other hand, yields between men and women show significant differences on specific land-use types that require more labor. For example, the average yield from monoculture rubber is significantly higher in men-dominated landscape than in women-dominated landscape because this land use is labor intensive, which women are constrained with due to their gender (reproductive) roles. In terms of rice, the yield becomes higher in women-dominated landscape under PES scheme because between agroforest and rice, women would choose rice due to the matrilineal system. The productivity difference between men and women is attributed to education, control over resources (i.e., land), access to inputs and services (e.g., fertilizer, extension and credit), and social norm (Croppenstedt et al., 2013). Studies linking these factors and may impact on the provisioning of ecosystem services at the landscape level are underway (i.e., under the CGIAR research program on forest, trees and agroforests.

We conclude that when designing sustainable policies it is important to consider gender-specific land-use decision making that would affect the provision of ecosystem services, especially in developing countries that have different gender roles or strong cultural aspect (such as matrilineal system). Furthermore, approaches such as ABM and RPG are effective in exploring the gender-specific objectives and goals within the locally perceived socio-cultural landscapes. 
Villamor and van Noordwijk., Incorporating gender specific land-use decisions in agent-based land use models

\section{ACKNOWLEDGMENTS}

The authors would like to acknowledge the CGIAR research program on Forest, Trees and Agroforests

(FTA) for the financial support of conducting this research study.

\section{REFERENCES}

Blackwood, E. (2008). Not your average housewife: Minangkabau women rice farmers in West Sumatra, In: Ford, M., Parker, L. (Eds.), Women and Work in Indonesia. Taylor \& Francis: Oxon, pp. 17-40.

Croppenstedt, A., Goldstein, M., Rosas, N., 2013. Gender and agriculture: inefficiencies, segregation, and low productivity traps. The World Bank Research Observer, 28, 79-109, doi: 10.1093/wbro/lks024.

Ekadinata, E. and Vincent, G. (2011). Rubber agroforests in a changing landscape: analysis of land use/ cover trajectories in Bungo district, Indonesia. Forest, Trees and Livelihoods, 20, 3-14.

Le, Q.B., Park, S.J., Vlek, P.L.G. and Cremers, A.B. (2008). Land-use dynamic simulator (LUDAS): a multiagent system model for simulating spatio-temporal dynamics of coupled human-landscape system. I. Structure and theoretical specification. Ecological Informatics, 2, 135-153.

Meinzen-Dick, R.S., Kovarik, C. and Quisumbing, A. (2014). Gender and Sustainability. Annual Review of Environment and Resources, 39(1), 29-55.

Müller, B., Bohn, F., Dreßler, G., Groeneveld, J., Klassert, C., Martin, R., Schlüter, M., Schulze, J., Weise, H. and Schwarz, N. (2013). Describing human decisions in agent-based models-ODD+ D, an extension of the ODD protocol. Environmental Modelling \& Software, 48, 37-48.

Parker, D.C., Manson, S.M., Janssen, M.A., Hoffmann, M.J. and Deadman, P.J. (2003). Multi-Agent Systems for the Simulation of Land-Use and Land-Cover Change: A Review. Annals of the Association of American Geographers, 93(2), 314-337.

Rahayu, S. (2009). Peran agroforestry karet dalam pelestarian spesies pohon: studi kasus di Desa Lubuk Beringin, Kecamatan Bathin III Ulu, Kabupaten Bungo, Provinsi Jambi: Sekolah Pasca Sarjana. Institut Pertanian Bogor.

van Noordwijk, M., Bizard, V., Wangpakapattanawong, P., Tata, H.L., Villamor, G.B. and Leimona, B. (2014). Tree cover transitions and food security in Southeast Asia. Global Food Security, 3(3-4), 200208.

van Noordwijk, M., Tata, H.L., Xu, J., Dewi, S. and Minang, P.A. (2012). Segregate or Integrate for Multifunctionality and Sustained Change Through Rubber-Based Agroforestry in Indonesia and China: Agroforestry - The Future of Global Land Use, In: Nair, P.K.R., Garrity, D. (Eds.). Springer Netherlands, pp. 69-104.

van Noordwijk, M. and Villamor, G.B. (2014). Tree cover transitions in tropical landscapes: hypotheses and cross-continental synthesis, GLPNews, pp. 33-37.

Villamor, G.B., Akiefnawati, R., van Noordwijk, M., Desrianti, F. and Pradhan, U. (2015). Land-use change and shifts in gender roles in central Sumatra, Indonesia. International Forestry Review, 17(2), 61-75.

Villamor, G.B., Desrianti, F., Akiefnawati, R., Amaruzaman, S. and van Noordwijk, M. (2014a). Gender influences decisions to change land use practices in the tropical forest margins of Jambi, Indonesia. Mitigation and Adaptation Strategies for Global Change 19(6), 733-755.

Villamor, G.B., Le, Q.B., Djanibekov, U., van Noordwijk, M. and Vlek, P.L.G. (2014b). Biodiversity in rubber agroforests, carbon emissions, and rural livelihoods: An agent-based model of land-use dynamics in lowland Sumatra. Environmental Modelling \& Software, 61, 151-165.

Villamor, G.B., Troitzsch, K.G. and van Noordwijk, M. (2013). Validating human decision making in an agent-based land-use model, In: Piantadosi, J., Anderssen, R.S., Boland, J. (Eds.), 20th International Congress on Modelling and Simulation. Modelling and Simulation Society of Australia and New Zealand: Adelaide, Australia, pp. 2110-2116.

Villamor, G.B., van Noordwijk, M., Djanibekov, U., Chiong-Javier, M. and Catacutan, D. (2014c). Gender differences in land-use decisions: shaping multifunctional landscapes? Current Opinion in Environmental Sustainability 6, 128-133. 